RODRIGUES, A.B.F. et al. Utilização de coleópteros na preparação de material osteológico. PUBVET, Londrina, V. 6, N. 3, Ed. 190, Art. 1281, 2012.

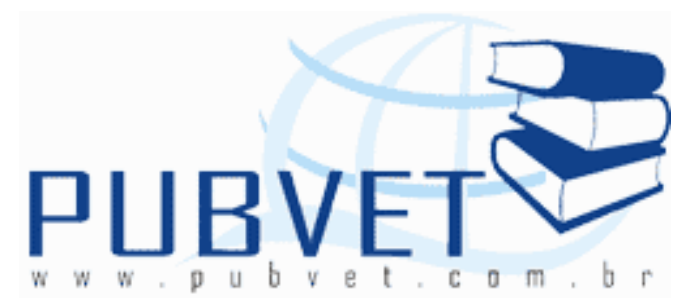

PUBVET, Publicações em Medicina Veterinária e Zootecnia.

\title{
Utilização de coleópteros na preparação de material osteológico
}

Ana Bárbara Freitas Rodrigues ${ }^{1}$; Ana Carolina Queiroz Lima ${ }^{2}$; Carlos Henrique de Oliveira Nogueira ${ }^{3}$; Paulo Moreira Bogossian ${ }^{4}$; Vinícius Novaes Rocha ${ }^{5}$

${ }^{1}$ Professor Associado, Laboratório de Morfologia e Patologia AnimalLMPA/CCTA/UENF- Av. Alberto Lamego, 2000 - CEP: 28013-602 - Parque Califórnia - Campos dos Goytacazes-RJ- Brasil.

${ }^{2}$ Médica Veterinária- Bolsista de Apoio ao ensino de graduação/ Universidade Estadual do Norte Fluminense Darcy Ribeiro (UENF) e-mail -cccarol@hotmail.com ${ }^{3}$ Discente do curso de Medicina Veterinária da UENF

${ }^{4}$ Médico Veterinário pela UENF

${ }^{5}$ Doutorando em Biologia-Universidade Estadual do Rio de Janeiro(UERJ).

\section{Resumo}

Este trabalho tem como finalidade divulgar a utilização de Dermestes maculatus na preparação de material osteológico de diferentes espécies animais e, ao mesmo tempo, contribuir para a diversificação da coleção osteológica da Seção de Anatomia da UENF. Seis animais de diferentes espécies tiveram seus esqueletos limpos pelos insetos. O procedimento de limpeza completa foi obtido em diferentes períodos de tempo e mantinha uma relação direta com o número de larvas e insetos adultos presentes nas colônias. No final da exposição, alguns 
RODRIGUES, A.B.F. et al. Utilização de coleópteros na preparação de material osteológico. PUBVET, Londrina, V. 6, N. 3, Ed. 190, Art. 1281, 2012.

esqueletos mostraram-se totalmente articulados, mantendo preservados os seus detalhes anatômicos. Fica comprovado que a utilização de Dermestes maculatus pode ser considerada um método muito eficaz para a preparação de coleções osteológicas, com objetivos didáticos e / ou científico.

Palavras-chave: Dermestes; osteologia; esqueleto.

\title{
Utilization of coleopteros in preparation of osteologic material
}

\begin{abstract}
This research is intented to show the use of dermestids in the preparation of osteologic material for different animal species and, at the same time, to contribute to the osteologic collection diversification of the Anatomy Center at UENF. Six animals from different species had their skeleton were cleaned by the insects. The complete cleaning procedure was obtained in different periods of time. It was closely related to the number of larval and adults in the colonies. At the end of the exposure, some skeletons revealed themselves totally articulated, keeping preserved their anatomic details. It is now proved that in this research the utilization of dermestids was the best method for the preparation of osteologic collections, with didatic and/or cientific objectives
\end{abstract}

Keywords: Dermestids; osteologic; skeleton.

\section{INTRODUÇÃO:}

A anatomia é considerada um ramo da ciência ocupada com a forma, a disposição e a estrutura dos tecidos e órgãos que compõem o organismo ${ }^{1}$. 0 termo anatomia, de origem grega, significa "cortar fora", daí a dissecação do cadáver representar o método mais tradicional e primordial de estudá-la. No entanto, os anatomistas, cada vez mais, vêm empregando inúmeras outras técnicas para suplementar o conhecimento da anatomia macroscópica obtida pelo 
RODRIGUES, A.B.F. et al. Utilização de coleópteros na preparação de material osteológico. PUBVET, Londrina, V. 6, N. 3, Ed. 190, Art. 1281, 2012.

uso do bisturi ${ }^{2}$. Com o desenvolvimento da ciência, cresceu a necessidade do acúmulo de espécimes (animais vertebrados, invertebrados e também vegetais) em coleções para servirem de base nas descrições de espécies novas, delimitações de suas distribuições geográficas entre outros estudos. 0 aperfeiçoamento de técnicas de preparação de animais se faz necessário, permitindo, desta forma, que certos animais sejam apresentados de forma mais estética ao público, ou que a maior parte de suas características, externas e internas, sejam preservadas para fins didáticos ${ }^{3}$. No que se refere às coleções osteológicas, é alarmante que quase um terço das espécies de aves não esteja representadas em nenhuma coleção do mundo. O mesmo deve acontecer com outros vertebrados negligenciados neste tipo de coleção ${ }^{4}$. Esqueletos são ferramentas importantíssimas tanto para pesquisa científica, na identificação de caracteres para análises anatômicas e filogenéticas, como para fins didáticos, ilustrando a estrutura corpórea. O crescimento de coleções osteológicas é uma ferramenta imprescindível para algumas ciências como a paleontologia e até mesmo a medicina veterinária ${ }^{3}$. Processos usuais de preparação de esqueletos como a maceração e o uso de substâncias cáusticas não atingem as necessidades, visto que, geralmente, desarticulam os esqueletos e com isso muitas informações anatômicas se perdem. A preparação de esqueletos utilizando insetos coleópteros tem maiores vantagens em relação aos processos já enumerados. As larvas de coleópteros, na limpeza dos ossos, podem facilmente atingir regiões do esqueleto de difícil acesso, como a região craniana, deixando todos os componentes ósseos limpos e bem visíveis. Como principais vantagens da utilização de insetos na preparação de esqueletos podem citar: odor muito menos desagradável do que na maceração, limpeza completa do exemplar e recuperação de exemplares totalmente articulados $^{5}$. A preparação e montagem de esqueletos não é uma prática tão simples quanto parece, deve ser considerada a complexidade estrutural óssea de alguns vertebrados, as proporções, às vezes, 
RODRIGUES, A.B.F. et al. Utilização de coleópteros na preparação de material osteológico. PUBVET, Londrina, V. 6, N. 3, Ed. 190, Art. 1281, 2012.

diminutas dos componentes ósseos e principalmente a sua fragilidade ${ }^{3}$. A preparação manual com uso de pinças, pequenas tesouras e bisturis despendem muito tempo e nunca se consegue uma limpeza perfeita, especialmente com relação aos ossos do esqueleto cefálico ${ }^{6}$. Quando se leva em conta a importância econômica dos insetos, normalmente, as primeiras espécies lembradas são as que, direta ou indiretamente, causam prejuízos materiais ou danos à saúde de plantas e animais, inclusive ao homem, muitas delas vistas como 'pragas'. Em sua relação com a espécie humana, porém, os insetos podem desempenhar muitas vezes um papel surpreendente. Esse é justamente o caso da entomologia forense, ciência que aplica o estudo dos insetos a procedimentos relacionados a investigações médico-criminais ${ }^{7}$. Os besouros, grupo de insetos pertencentes à ordem Coleóptera, são o segundo grupo de insetos de maior interesse forense no Brasil, sendo encontrados nas carcaças tanto em sua fase adulta de desenvolvimento, quanto na fase imatura ${ }^{8,9}$. Algumas espécies de coleópteros aparecem frequentemente associadas aos cadáveres, pois se alimentam de carne ou de artrópodes que se encontram neste meio cadavérico. Os estágios larvares destes coleópteros são necrófagos ${ }^{10,11}$. Um estudo da fauna entomológica da reserva biológica do Atol das Rocas revelou que Dermestes cadaverinus, da família Dermestidae, ordem Coleoptera, em sua forma larvar e adulta, quando presentes em corpos de pássaros mortos, aceleravam o processo de decomposição ${ }^{12}$. Os dermestídeos, adultos e larvas, são saprófagos ou necrófagos, alimentam-se da matéria orgânica deixada por outros destruidores de carcaças de animais, músculos e tendões, que ficam presos aos ossos. Alguns pesquisadores preconizam o uso de Dermestes maculatus para a limpeza dos esqueletos de pequenos animais ${ }^{13}$. O tempo de permanência dos exemplares sob a ação dos insetos depende das condições da colônia em termos de número de larvas. O ciclo biológico de Dermestes maculatos se estende por aproximadamente 60 dias, dos quais 10 dias em condição de pulpa e 11 dias em 
RODRIGUES, A.B.F. et al. Utilização de coleópteros na preparação de material osteológico. PUBVET, Londrina, V. 6, N. 3, Ed. 190, Art. 1281, 2012.

estágio de larva. É de grande valia o monitoramento diário do dermestário, impedindo desta maneira que por falta de alimento os insetos passem a destruir as cartilagens das extremidades dos ossos e os ligamentos que os mantém articulados $^{6}$. A preparação de esqueletos pode ter finalidade científica, para qual, normalmente, os ossos ficam totalmente desarticulados ou semi-articulados, ou ainda para fins didáticos e de exposição, quando devem permanecer articulados e montados em posição de vida ${ }^{3}$. O objetivo deste trabalho é divulgar a utilização de coleópteros, dermestídeos, na preparação de material osteológico de diferentes espécies animais e ao mesmo tempo diversificar a coleção osteologica da Seção de Anatomia da Universidade Estadual do Norte Fluminense Darcy Ribeiro.

\section{MATERIAL E MÉTODOS:}

Seis animais: uma iguana, um suíno, um morcego, uma coruja, um ferret e uma rolinha, todos oriundos do Município de Campos dos Goytacazes, vieram a óbito e foram doados para Seção de Anatomia Veterinária da Universidade Estadual do Norte Fluminense. Os animais foram devidamente preparados para limpeza dos seus esqueletos por dermestídeos, segundo orientações contidas no Manual de técnicas de coleta e prepação de vertebrados para fins científicos e didáticos ${ }^{3}$. Utilizando bisturi, tesoura e pinça de dissecação as peles dos animais foram completamente separadas das carcaças. Também foram retiradas as vísceras e os encéfalos e, em seguida, as carcaças foram encaminhadas para o setor de preparação de esqueleto. Foi efetuada a remoção máxima da musculatura das diferentes carcaças e estas foram lavadas, em água corrente, e secas com auxílio de papel toalha. Em seguida, as carcaças foram mergulhados em uma solução de álcool $96^{\circ}$, por um período médio de uma semana e ao final deste período foram mantidas em temperatura ambiente, também por uma semana, para a evaporação total do álcool. Finalmete, cada 
RODRIGUES, A.B.F. et al. Utilização de coleópteros na preparação de material osteológico. PUBVET, Londrina, V. 6, N. 3, Ed. 190, Art. 1281, 2012.

carcaça foi colocada, em posição definitiva, dentro de uma caixa plática, devidamente preparada, contendo larvas e insetos adultos (dermestário). Para a perfeita atuação dos insetos, os dermestários foram mantidos em condições adequadas de temperatura e iluminação. Monitotamentos diários da limpeza dos esqueletos por dermestídeos foram realizados com o intuito de identificar o momento exato de retirada dos esqueletos. Uma limpeza prévia dos esqueletos, com auxílio de pincel, foi realizada para a retirada do excesso de larvas. As larvas que ainda restaram foram removidas do esqueleto por intermédio de inseticidas. Posteriomente os esqueletos form lavados e clarificados em solução de peróxiodo de hidrogênio $\left(\mathrm{H}_{2} \mathrm{O}_{2}\right)$. Finalmente foram efetuados reparos nos esqueletos articulados e semi-articulados com o auxílio de adesivo instantâneo e arames de fixação. Todos os esqueletos preparados foram expostos em coleções osteológicas e tiveram fins didáticos e científicos.

\section{RESULTADOS E DISCUSSÃO:}

A utilização de dermestídeos na limpeza de esqueletos se mostrou muito vantajosa, visto a capacidade desses insetos em atingir regiões do esqueleto de difícil acesso ${ }^{5}$. Os dermestídeos além de terem proporcionado uma limpeza completa dos esqueletos expostos, deixando todos os componentes ósseos limpos e bem visíveis, foram capazes de preparar esqueletos frágeis e com uma considerável complexidade das estruturas ósseas ${ }^{3,5}$. Foi observada uma variação em relação ao tempo de permanência de cada exemplar sob a ação dos insetos. A completa limpeza dos esqueletos foi obtida em aproximadamente quatro meses, no caso da iguana, em um mês para o suíno e o ferret, por volta de vinte dias para a rolinha e aproximadamente dez dias no caso do morcego e da coruja. Foi detectado que o tempo de exposição dos exemplares estava intimamente relacionado com as condições das colônias em termos de números de $\operatorname{larvas}^{6}$. Os esqueletos da iguana (Figura 1), do ferret, da rolinha, do morcego e da coruja, ao 
RODRIGUES, A.B.F. et al. Utilização de coleópteros na preparação de material osteológico. PUBVET, Londrina, V. 6, N. 3, Ed. 190, Art. 1281, 2012.

final do período de exposição aos insetos se mostraram totalmente articulados, mantendo conservados os detalhes anatômicos do esqueleto.

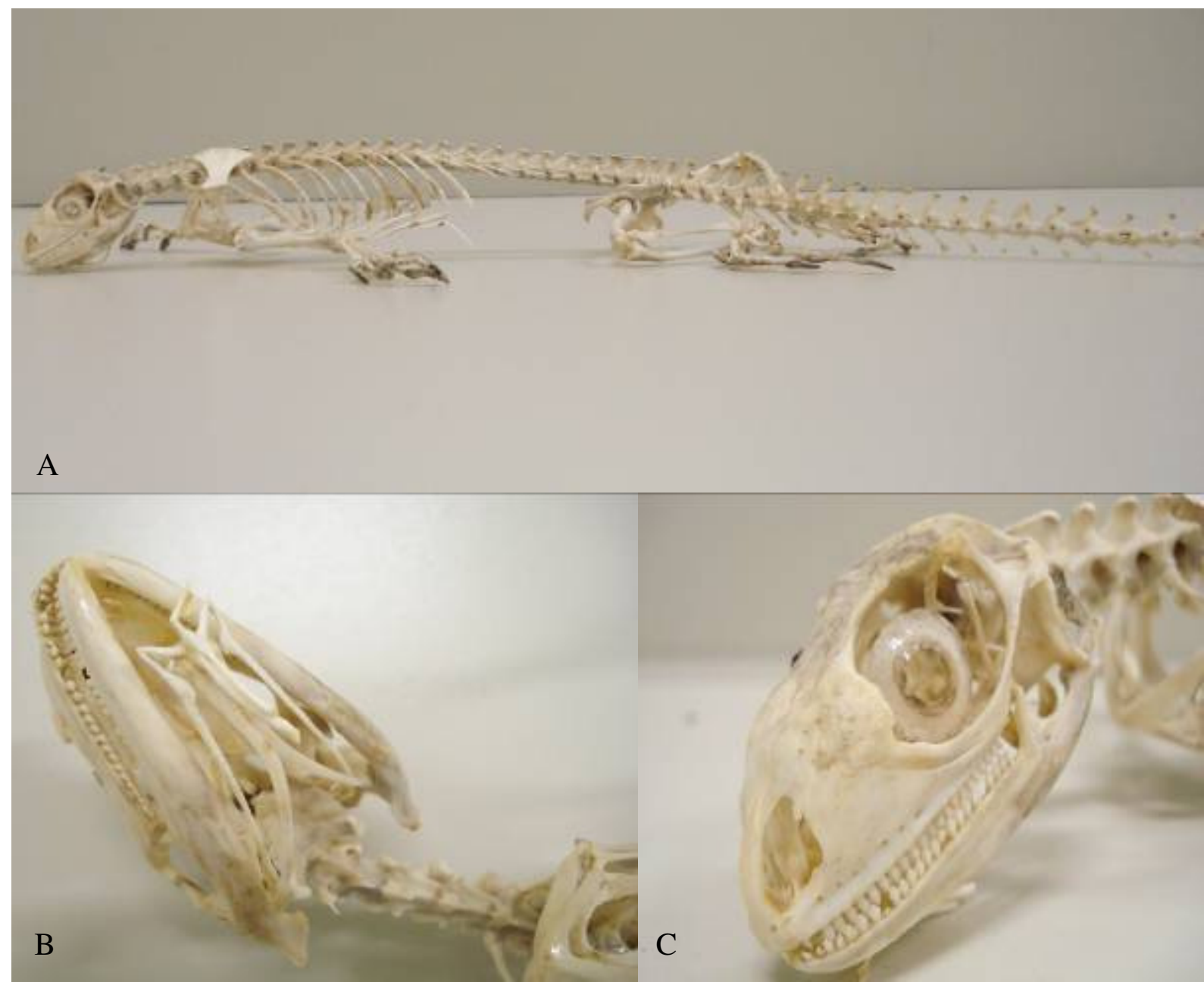

Figura 1- Esqueleto axial de Iguana: A- Esqueleto axial totalmente articulado; B e C-Vista ventral e dorso lateral da cabeça demonstrando estruturas ósseas articuladas.

Em relação ao suíno, por se tratar de um animal novo, com maior quantidade de cartilagem formado o esqueleto, foi obtido um esqueleto semiarticulado $^{6}$. Falhas em relação ao tempo de exposição proporcionaram uma semiarticulação do esqueleto, com destruição das cartilagens dos ossos e dos 
RODRIGUES, A.B.F. et al. Utilização de coleópteros na preparação de material osteológico. PUBVET, Londrina, V. 6, N. 3, Ed. 190, Art. 1281, 2012.

ligamentos. Fica comprovado que, a utilização de dermestídeos constitui o método mais prático na preparação de coleções osteológica ${ }^{12,13}$. No entanto, concluímos que dependendo do interesse de cada pesquisador a preparação de esqueletos por intermédio de dermestídeos pode ter fins científicos, onde os ossos ficam totalmente desarticulados ou semi-articulados ou fins didáticos e de exposição, quando os mesmo permanecem articulados e montados para serem expostos.

\section{REFERÊNCIAS BIBLIOGRÁFICAS:}

1.ELLENPORT,C.R..In: SISSON \& GROSSMAM.Anatomia dos Animais Domésticos. 5a Ed..Rio de Janeiro:Guanabara Koogan. 1986, p 3-18..

2. DYCE, K.M;SACK,W.O.; WENSING,C.J.G. In: .Tratado de Anatomia Veterinária. Rio de Janeiro: Elsevier, 2004, p.1-31.

3.AURICCHIO,P.;SALOMÃO,M.G., Técnicas de coleta e preparação de vertebrados para fins científicos e didáticos. São Paulo: Arujá: Instituto Pau Brasil de História Natural, 2002,348p.

4.MATTHIESEN, D.G. La curación de las colecciones osteológicas de aves. In: ESCALANTEPLIEGO. P. (ed) Curacion Moderna de Colecciones Ornitológicas. Washington :American Ornithological Union.,1993, p. 41-68

5. RODRIGUES, H. Técnicas Anatômicas . Vitória:1998. 222p.

6. FRANCO, T.C.B., BARBOSA, D.R., SANTOS, R.S. Arq. em Conex., 7, 2001.

7. GOMES, L.; VON ZUBEN,C.J.Rev. Ciênc. Hoje, 35 (208):28-31, 2004.

8.CARVALHO, L.M.L;THYSSEN,P.J.;LINHARES,A.X. Brazil Mem. Inst. Oswaldo Cruz, 95 (1):138p.

9.BARBOSA,R.R.;QUEIROZ,M.M.C.;GREDILHA,R.;LIMA,A.F.;MELLO, R.P. In: XXI CONGRESSO BRASILEIRO DE ENTOMOLOGIA, Recife-PE, 2006..

10. BRAACK, L. Oecologia, 2: 402-409, 1987.

11. CATTS, E.P.;GOFF, M.L. An.l Rev. of Entomol., .37:253-272, 1992.

12.ALMEIDA,C.E.;MARCHON-SILVA,V.;RIBEIRO,R.;SERPA-FILHO, A.;ALMEIDA,J.R.;COSTA,JRev. Bras. Biol. 60(2):66-72, 2000.

13.COSTA LIMA, A. Insetos do Brasil - Coleópteros. 8 Tomo, capítulo XXIX, 2a Parte Escola Nacional de Agronomia, Série Didática, n.10, 1953. 323p. 